\title{
Decision-making in district health planning in Uganda: does use of district-specific evidence matter?
}

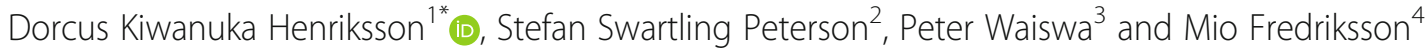

\begin{abstract}
Background: In a decentralised health system, district health managers are tasked with planning for health service delivery, which should be evidence based. However, planning in low-income countries such as Uganda has been described as ad hoc. A systematic approach to the planning process using district-specific evidence was introduced to district health managers in Uganda. However, little is known about how the use of district-specific evidence informs the planning process. In this study, we investigate how the use of this evidence affects decision-making in the planning process and how stakeholders in the planning process perceived the use of evidence.
\end{abstract}

Methods: A convergent parallel mixed-methods study design was used, where quantitative data was collected from district health annual work plans for the financial years 2012/2013, 2013/2014, 2014/2015 and 2015/2016 as well as from bottleneck analysis reports for 2012, 2013, 2014 and 2015. Qualitative data was collected through semi-structured interviews with key informants from the two study districts.

Results: District managers reported that they were able to produce more robust district annual work plans when they used the systematic approach of using district-specific evidence. Approximately half of the prioritised activities in the annual work plans were evidence based. Procurement and logistics, training, and support supervision activities were the most prioritised activities. Between $4 \%$ and $5.5 \%$ of the total planned expenditure was for child survival, of which $47 \%$ to $94 \%$ was from donor and other partner contributions.

Conclusion: District-specific evidence and a structured process for its use to prioritise activities and make decisions in the planning process at the district level helped systematise the planning process. However, the reported limited decision and fiscal space, inadequate funding and high dependency on donor funding did not always allow for the use of districtspecific evidence in the planning process.

Keywords: District health system, planning, decision-making, evidence, work plans, Uganda

\section{Background}

The health sector in Uganda has undergone several changes and reforms since the Harare Declaration, which introduced the district health system (DHS) [1] and the introduction of decentralisation in its current form in 1997 [2]. Planning, which is one of the core activities within the DHS, has been affected, during this period, by these policy changes and met practical hindrances such as political and technical resistance to effective decentralisation, a rapid increase in the number of districts [3], limited

\footnotetext{
* Correspondence: dorcus.kiwanuka@ki.se; dorcus.kiwanuka@gmail.com ${ }^{1}$ Karolinska Institutet, Stockholm and Uppsala University, Uppsala, Sweden Full list of author information is available at the end of the article
}

financial resources and decision space [4], and implementation of vertical programmes $[5,6]$, to mention just a few. The weakened capacity of the Ministry of Health $(\mathrm{MoH})$ due to inadequate number of staff to effectively coordinate, support and supervise the growing number of districts and absence of a regional level, have also affected the planning process [7].

In 1997, Uganda took on political, administrative and fiscal decentralisation, thereby transferring administrative, political and fiscal authority from the central government to the local government authorities, mainly in the form of devolution $[2,8]$. Unlike many other countries, Uganda has no functional 'intermediate level' such

(c) The Author(s). 2019 Open Access This article is distributed under the terms of the Creative Commons Attribution 4.0 International License (http://creativecommons.org/licenses/by/4.0/), which permits unrestricted use, distribution, and 
as provinces or regions [9], although this level has been planned for and included in the health sector development plan 2015/2016-2019/2020 [10]. The District Council composed of elected officials is the highest political authority in the district and makes the final decision on approval of the annual district health work plan. The administrative and technical team at the district is divided into directorates, including for health, which are responsible for developing annual work plans [2].

The provision of healthcare is the responsibility of two levels of government - the central (macro) and the local (meso and micro) levels (Fig. 1). The DHS is part of the district local government [2] and is a self-contained segment of the national health system. The DHS is responsible for the delivery of health services, planning, management and implementation of policies [7].

Although planning should be evidence based to prioritise activities [11, 12], in low-income countries (LICs) such as Uganda, priority-setting has been described as ad hoc [13]. It has been documented that health managers make decisions based on national and donor priorities and, in some cases, based on previously funded activities [14-17]. This situation has been attributed to, amongst other factors, the lack of tools to aid priority-setting and decision-making $[16,17]$. Even when tools are available, they are not always used by decision-makers in LICs as they lack credibility for priority-setting in low-resource settings $[18,19]$. Many of these tools have been tested in pilot settings and do not evaluate the impact on actual priority-setting [19].

Similarly, in Uganda, the lack of tools to assess performance in the DHS prevents the identification of gaps in service delivery and the definition of priorities for actions to bridge the gaps during the annual planning process [16]. A systematic approach of using district-specific evidence in the planning process was introduced to the district health management teams (DHMT) in 21 districts, by the Community and District Empowerment for Scale-up (CODES) project. The CODES project targeted key interventions to reduce child deaths due to diarrhoea, pneumonia and malaria, for which the planning processes focused on child survival. Results on the effect of the interventions on child survival are being finalised. A specific focus of the project was to build the capacity of the DHMT to use district-specific evidence in the planning process [20].

District-specific evidence in this study refers to the data that was collected through routine Health Management Information Systems and other surveys, for example, Lots Quality Assurance Surveys. Evidence also includes information from community dialogues with care givers of children under 5 years of age, health workers and village health teams. The structured process refers to how this evidence was analysed by the DHMT to identify gaps in service delivery and prioritise solutions to overcome those gaps [20].

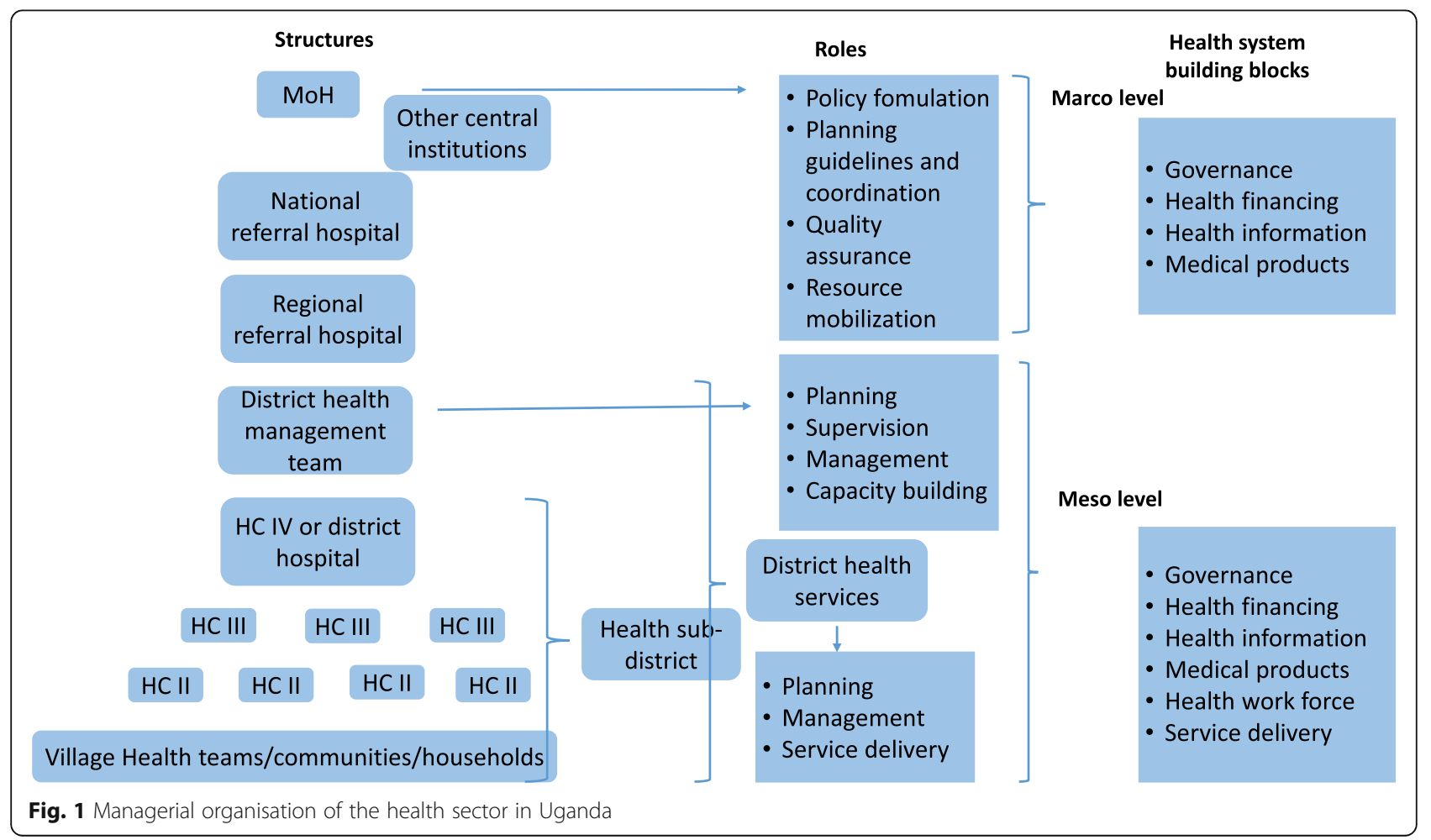


The use of evidence in the field of medicine is usually understood as evidence-based medicine, which is defined as "the conscientious, explicit, and judicious use of current best evidence in making decisions about the care of individual patients" [21, 22]. Over the years, evidence-based health policy-making has become increasingly common [23, 24], thus shifting the focus from the individual level to the population level [25].

What constitutes 'evidence' in the area of evidence-based and evidence-informed policy-making has been subject of discussion. Rychetnik et al. [26] define evidence as facts or testimony in support of a conclusion, statement or belief. Oxman et al. [27] have a similar definition, saying that evidence is concerned with actual or asserted facts intended for use to support a conclusion. However, both of these definitions are broad and do not speak of the context within which evidence is used, what is considered evidence and who uses the evidence [26] .

Decisions are not made solely based on evidence, but other factors are considered as well, such as the priorities at the time the policy is decided, the context and financial resources, and the actors involved [28]. Therefore, the use of evidence in policy-making involves a complex process of interactions between policy actors and different powers, interactions and agendas [28], and can be affected by institutional characteristics and the political process.

Evidence-based planning, as defined by Steen [29], is a process of basing decisions about ways to address a problem on information to achieve the best results. Although evidence-based planning is not as commonly referred to in the literature, it follows similar principles as evidence-based or evidence-informed policy-making, with the primary purpose being the use of evidence to inform decision-making.

The CODES project introduced the Tanahashi bottleneck analysis tool that enabled the DHMT to identify bottlenecks to implementation of key interventions for diarrhoea, pneumonia and malaria. Casual analysis was done guided by a management checklist. Solutions were later subjected to a prioritisation matrix that had a scale of 1 to 3 in the areas of supporting evidence, policy, capacity, affordability, acceptability and equity. Examples of bottlenecks were loss to follow-up and high dropout rate for routine immunisation and inadequate utilisation of malaria case management services. Details on the CODES project is described elsewhere [16, 30-32].

This process of identification of bottlenecks and prioritisation of solutions was conducted each year for each of the districts $[16,20]$ and documented in a bottleneck analysis report. The districts then planned for activities during the district annual planning process, based on the analysis of district-specific evidence, resulting in a district health annual work plan. The district health annual work plan is a document that gives a detailed account of how the district proposes to accomplish health service delivery [33].

The tools introduced by the CODES project to facilitate the use of district-specific evidence in the planning process were appreciated and adopted into the planning process. However, there were barriers such as a perceived lack of decision and fiscal space, politicians with their own priorities, gaps in human resources and inadequate health information systems [4, 34]. Another challenge was the central or national level priority-setting [7, 33, 35].

The $\mathrm{MoH}$ in Uganda, with the experience gained from the CODES project, is advocating for the use of district-specific evidence in the district planning process [33]. Thus, the MoH incorporated use of district-specific information in the new planning guidelines that are being rolled out at the district level [33]. However, little is known about how the use of district-specific evidence informs the planning process. For instance, what kind of priorities end up in the district health annual work plans after gaps have been identified? How does central priority-setting affect the district planning process? Therefore, the aim of the study was to investigate to what extent district-specific evidence informed prioritisation of child survival activities in the annual district work plans and how stakeholders in the planning process perceived the use of evidence. Results from this study will contribute to the body of knowledge on the use of district-specific evidence in the district planning process.

\section{Methods}

\section{Study site}

The study was conducted in two purposively selected districts in Uganda [36], chosen because they were introduced to a systematic approach which utilised tools to facilitate the use of district-specific evidence in the planning process [20] and had used the approach for over 4 years. One of the districts in the study was established in 2010 and has a population of approximately 150,000 people. For this study, it is referred to as district A. District B has a population of approximately 300,000 people and was established in the 1990s. Both districts are mainly rural, with approximately $60 \%$ of the people in both districts aged 18 years and under. See details in Table 1.

\section{Study design and data collection}

A convergent, parallel, mixed-methods design was used. Qualitative and quantitative data were collected separately within the same period and analysed separately, and the results were converged during interpretation $[37,38]$ (see Fig. 2 for the study procedure). This study design was used because it allowed for different but 
Table 1 District demographics

\begin{tabular}{lll}
\hline Demographics & District A & District B \\
\hline Approximate $^{a}$ total population & 300,000 & 150,000 \\
Year of creation & 1990 & 2010 \\
Approximate rural population & 200,000 & 140,000 \\
Approximate urban population & 100,000 & 10,000 \\
Number of health facilities & 20 & 14 \\
\hline
\end{tabular}

${ }^{\mathrm{a}}$ Approximates were used to keep districts anonymous

complementary data collection on the same topic and merging of results during interpretation, which facilitated a broader understanding of how district-specific evidence informed decision-making in the planning process $[39,40]$.

Quantitative information was collected from the district health annual work plans for the financial years $2012 / 2013,2013 / 2014,2014 / 2015$ and $2015 / 2016$ as well as from bottleneck analysis reports for 2012, 2013, 2014 and 2015, which were outputs of the bottleneck analysis process. To further understand how the use of local evidence affected the planning process and its perceived benefits, qualitative information was collected using semi-structured interviews with eight key informants [41, 42], four from each district. The key informants were purposefully selected [36] due to their involvement and knowledge of the district planning process. The interview guide used for the semi-structured interviews was developed based on the WHO decentralisation analysis framework [43] (Table 2). The framework was used because it considers the background of decentralisation and organisational processes and systems in the health sector under decentralisation. At the same time, the framework takes into account the difficulty of establishing direct casual links to changes within the health system. The framework also emphasises the need to search for alternative explanations for changes that take place in the health system [43].

\section{Study team}

The research team consisted of two Ugandan Public health specialists (DKH and PW) with experience as heads of a DHT, a Swedish health systems specialist (SSP) with previous experience working in Uganda, and a Swedish researcher in health and political reforms (MF). No one on the team was working within the district health system.

\section{Analysis}

Quantitative and qualitative data analyses were performed independently of each other. For the quantitative data, a descriptive analysis of the district health annual work plans and bottleneck analysis reports was conducted [44]. The bottleneck analysis was to establish which child survival activities were included in the work plans concerning the identified bottlenecks and how these activities were financed. Results were presented in graphs and figures. Thematic analysis [45-47] was conducted on the quantitative data to classify responses within themes related to use of district-specific evidence in the planning process and allocation of financial resources.

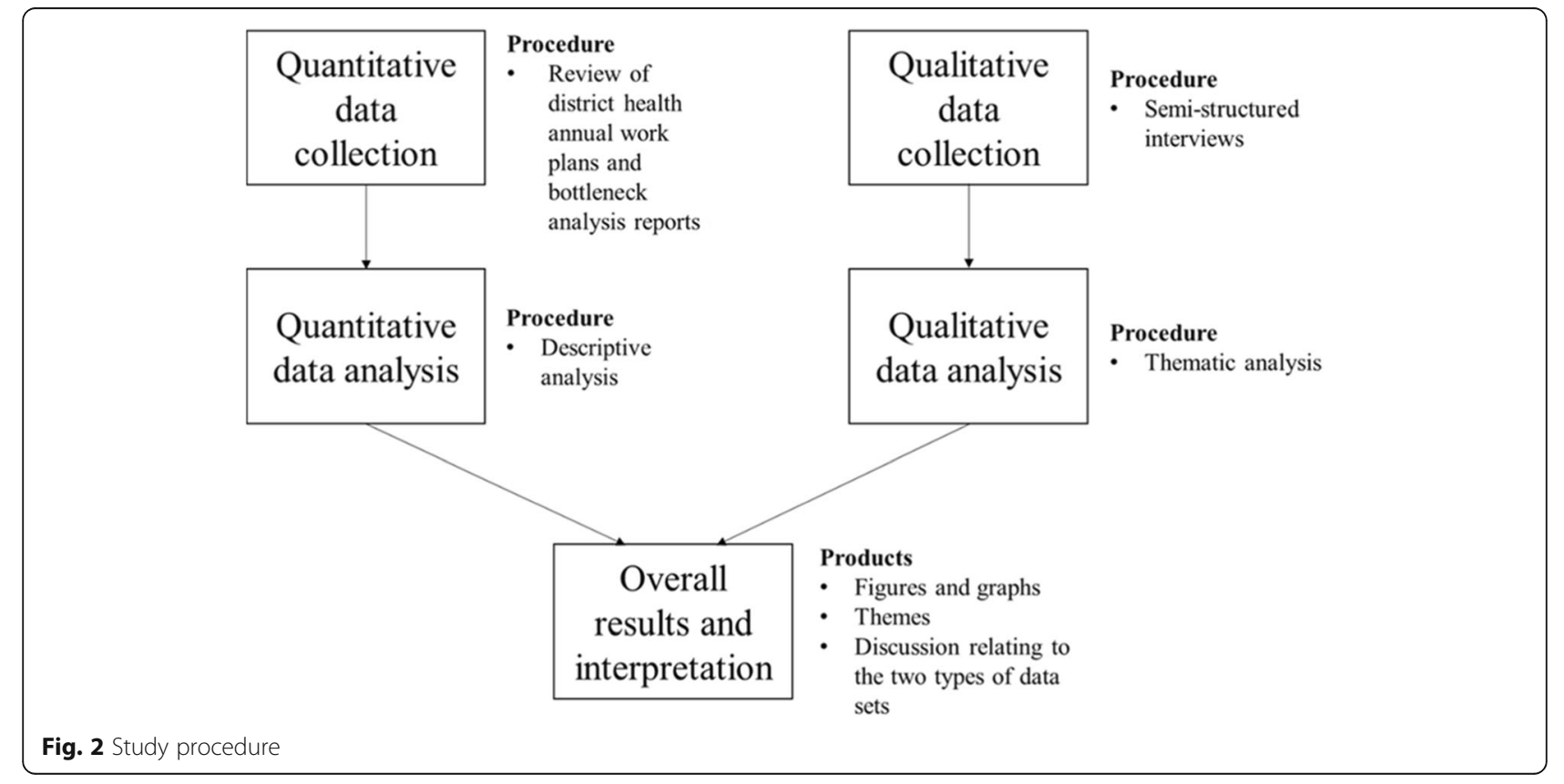


Table 2 Interview guide for key informant interviews

Objective/theme
and its purpose
Perceived outcomes of
using local evidence in
using local evidence in the planning process
How the use of locally generated data has affected the planning process and resource allocation for child survival activities

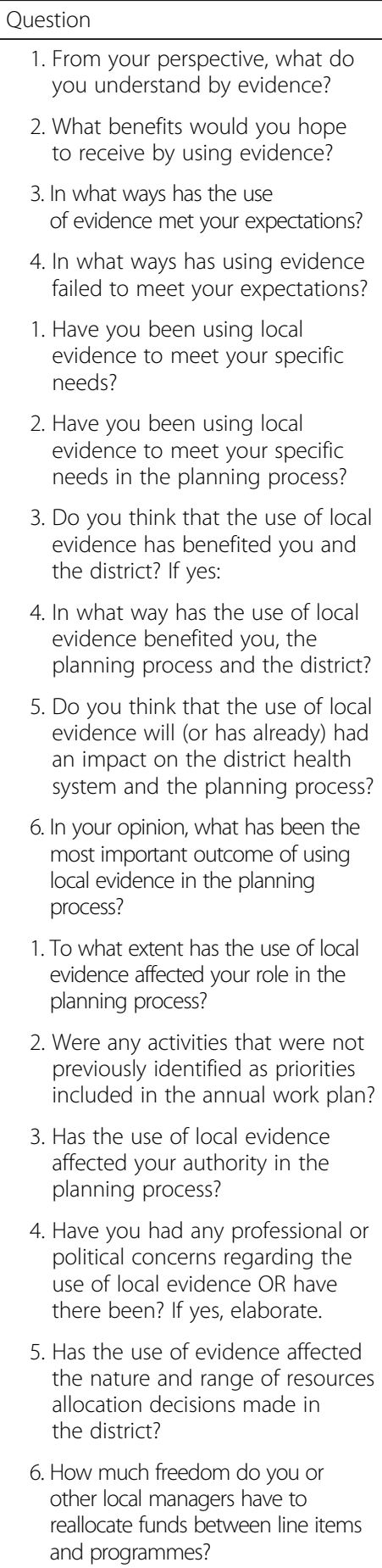

3. In what ways has the use of evidence met your expectations?

4. In what ways has using evidence failed to meet your expectations?

1. Have you been using local evidence to meet your specific needs?

2. Have you been using local evidence to meet your specific needs in the planning process?

3. Do you think that the use of loca evidence has benefited you and the district? If yes:

4. In what way has the use of local evidence benefited you, the planning process and the district?

5. Do you think that the use of local evidence will (or has already) had an impact on the district health system and the planning process?

6. In your opinion, what has been the most important outcome of using local evidence in the planning process?

1. To what extent has the use of local evidence affected your role in the planning process?

2. Were any activities that were not previously identified as priorities included in the annual work plan?

3. Has the use of local evidence affected your authority in the planning process?

4. Have you had any professional or political concerns regarding the use of local evidence OR have there been? If yes, elaborate.

5. Has the use of evidence affected the nature and range of resources allocation decisions made in the district?

6. How much freedom do you or other local managers have to reallocate funds between line items and programmes?

Budgets for wages and medicines were excluded from the budget analysis. It was not possible to estimate, by analysing the annual health work plans, how much time each employee devoted to child survival activities each year or the district expenditure on medicines related to child survival.

\section{Results}

Inclusion of proposed actions to identified gaps in the district health annual work plans

About half of the activities defined during the bottleneck and casual analysis process were included in the annual health work plan. The number of proposed activities increased by 13 and 10 from 2012/2013 to 2015/2016 in districts $A$ and $B$, respectively. However, the proportion of the defined solutions that were included in the district annual health work plan was about the same over the 4-year period. In district A, $57 \%$ of identified solutions were included in the annual work plan in 2012/2013 and $60 \%$ in $2015 / 2016$. In district B, $100 \%$ of identified solutions were prioritised in the annual health work plan in $2012 / 2013$ and only $40 \%$ in $2015 / 2016$.

The district managers also reported the inclusion of identified priorities into the work plans. However, they acknowledged that activities, even if included in the work plans, could not always be implemented because they sometimes did not have the power to take the necessary decisions themselves. One of the managers said:

"We are understaffed, but we do not have that power to say, 'if the staff is not enough let us recruit more.' So, the evidence is there that we lack staff, but there is no way we can fill that gap because we are not in that position to do so." Manager, district A

Activities that either had no direct financial implications or were considered to have very high financial implications were not always included in the annual health work plans, for example, procurement of expensive equipment.

"Evidence can help us plan, but again, plans must be backed up with a budget or money. So we only plan within the expected budget. Those [activities] that are expensive we cannot plan for them, we keep on postponing them." Manager, disrict B

Child survival activities prioritised in the district health annual work plans

A wide range of child survival activities were prioritised in the district health annual work plans. For purposes of this analysis, activities were categorised into (1) support supervision, (2) planning/meetings, (3) mobilisation and advocacy, (4) data-related activities, (5) training, (6) logistics and procurement, and (7) immunisation outreach. These categories were used because they represented all child survival 
Table 3 Categories used for the work plan analysis

\begin{tabular}{|c|c|}
\hline Categories & Description \\
\hline Support supervision & $\begin{array}{l}\text { All support supervision activities related to child survival interventions irrespective of who the supervisor or } \\
\text { supervisee was }\end{array}$ \\
\hline Planning/meetings & All meetings related to work planning activities \\
\hline Mobilisation and advocacy & Activities related to providing information and advocating for child survival interventions \\
\hline Data & Activities related to data collection for child survival activities \\
\hline Training/mentorship & Training activities related to the provision of child survival services \\
\hline Logistics and procurement & $\begin{array}{l}\text { Activities related to reproduction, purchase and distribution of child survival-related commodities apart from } \\
\text { procurement of medicines }\end{array}$ \\
\hline Outreaches for immunisation & Immunisation outreaches conducted \\
\hline
\end{tabular}

activities in the district health annual work plans (see Table 3 for a description of the categories).

Figure 3 shows that the majority of activities in the work plans were in the categories of logistics and procurement, support supervision, and training.

Further analysis of the procurement and logistics category, which accounted for the majority of the planned activities, showed variation in the kind of activities that were prioritised in each of the districts (Fig. 4). This variation in activities could have resulted in decisions being informed by district-specific evidence.

\section{Funding for child survival activities}

There was an increase in the planned budget for child survival activities between 2012/2013 and 2015/2016 in both districts. In district $\mathrm{A}$, the planned expenditure

a Child survival activities prioritised in work plans in district A

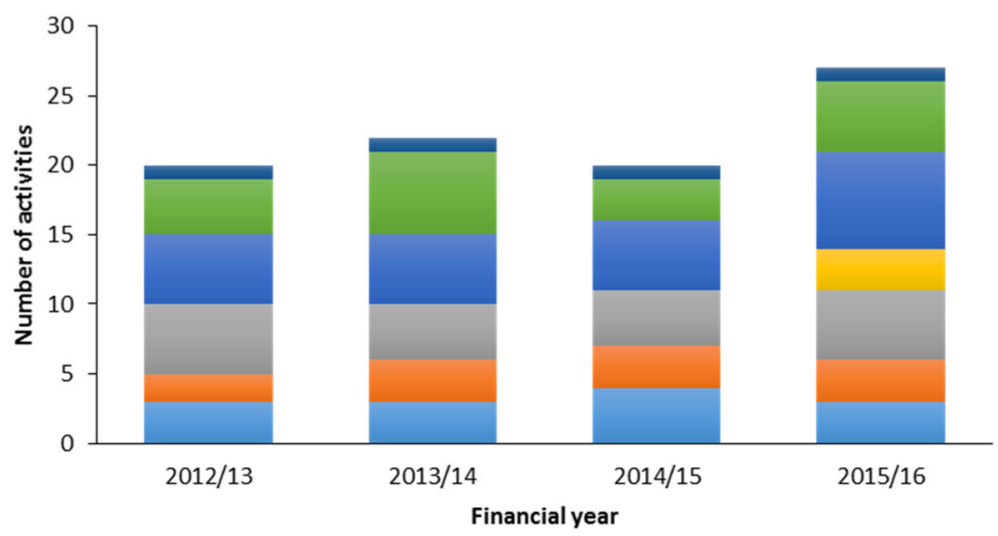

b Child survival activities prioritised in work plans in district B

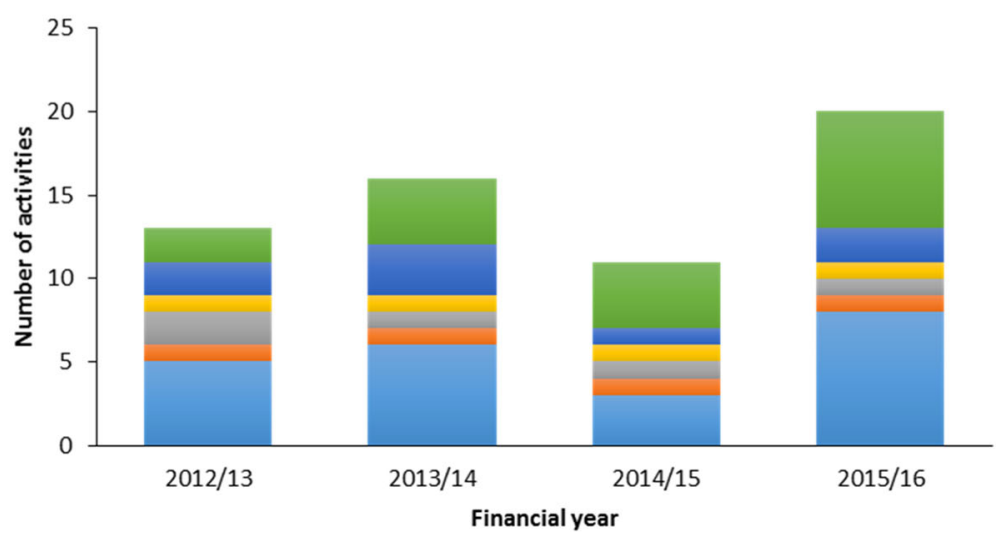

Fig. 3 Child survival activities included in the district annual health work plans for districts $\mathbf{a}$ and $\mathbf{b}$ 
increased from US\$ 4550 to US\$ 45,185, while in district B it rose from US\$ 6626 to US\$28,327. Child survival activities accounted for between $4 \%$ and $5.5 \%$ of the total planned expenditure on health services with per capita funding of US\$ 0.3 and US\$ 0.1 in districts A and B, respectively (Fig. 5a).

Although funding for child survival activities increased over the 4-year period, the levels were still low, and one of the district managers emphasised this:

"The funding is very, very little when you look at what we have planned and what has come as a contribution from the PHC [primary healthcare], and funds are minimal." Manager, district A

\section{Sources of funding for child survival activities}

There was a variation in the sources of funding over the four financial years (Fig. 5b, c). Government funding for child survival activities over the 4-year period, on average, accounted for $16 \%$ and $12 \%$ in district A and B, respectively. During the same period, donors and other partners contributed most of the funding for child survival activities, ranging from $47 \%$ to $94 \%$. In district A, over the 4-year period, UNICEF provided the most significant proportion of funding for child survival activities (44\%), while in district B, the Global Fund for HIV/ AIDS, Tuberculosis and Malaria provided $38 \%$ of the funding. Local government revenue (local revenue) accounted for the least amount of funding for child survival activities.

Results from both districts showed that the districts were dependent on partner/donor funding for child survival activities, although donors sometimes had their own priorities that were not necessarily those informed by the district-specific evidence. For example, the geographical area of implementation of programmes may not necessarily be in the areas that have the most need. The managers also expressed dependence on partner funding:

"So, we still feel that the money is little and if we had no partners, I think we would not be doing anything." Manager, district B

District managers reported that they were further constrained by the difficulty in reallocating resources as the funding came with guidelines for its use and could not be easily reallocated.

"If they [funds] are conditional, they have guidelines that come with those funding; they are not supposed to be reallocated, they are supposed to be used for whatever activities that they are supposed to do. If it is immunisation, it must be immunisation, not any other thing." Manager, district A

Outcomes of using local evidence in the planning process District managers reported that the use of district-specific evidence in planning was minimal before the introduction of evidence-based planning by the CODES project. They also stated that they were able to prioritise activities backed by evidence and produce more robust work plans. For instance, one of them said:

"I must say the work plans we have now are more real and genuine and factual. Using data has enabled us to have realistic work plans." Manager, district A

The managers also reported having fewer disagreements with elected officials when evidence was used in the planning process, which made their work easier than before. DHMT members also said that using district-specific evidence encouraged dialogue and better teamwork and allowed them to think outside the box for innovative solutions to identified problems.

"I think the most important [outcome] is that the process has inculcated in us the habit of discussion, of dialogue regarding deciding what is important for the district." Manager, district A

"Some few innovations have resulted from this; we might not measure their effect now but maybe in future. For example, we set up an intensive care unit [for children], it is not big, but an area with everything available, and kids are better." Manager, district $B$

\section{Understanding of evidence in the planning process}

Despite having a different understanding of the meaning of evidence, district managers said that evidence was the data they collect for the health department. Some of the respondents understood evidence as having proof about something, or that something works, while others thought that it refers to the use of quantitative data that was collected through Health Management Information Systems or surveys like Lots Quality Assurance Surveys. Others reported that evidence was information that was relevant to establishing the actual situation of the health department irrespective of its source and this could include community members and information collected from other sources, for example, from the political or religious leaders in the district.

"I think evidence means using data and facts derived from data, so using evidence is somehow connected to data." Manager, district A 


\section{a \\ Procurement and logistics activities in district A

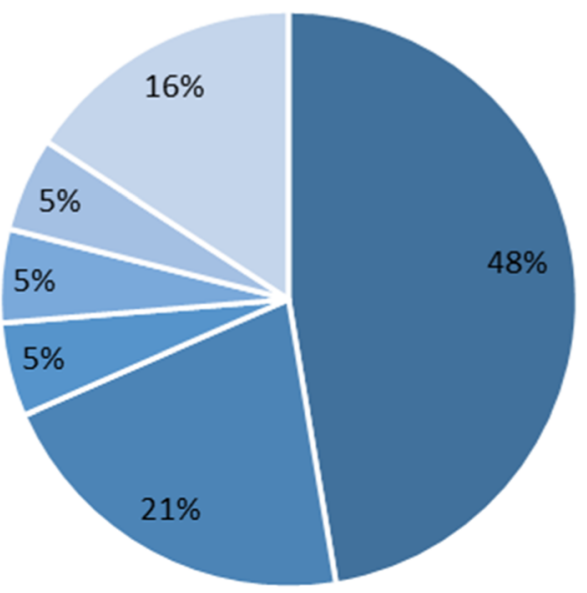 \\ b \\ Procurement and logistics activities in district B}

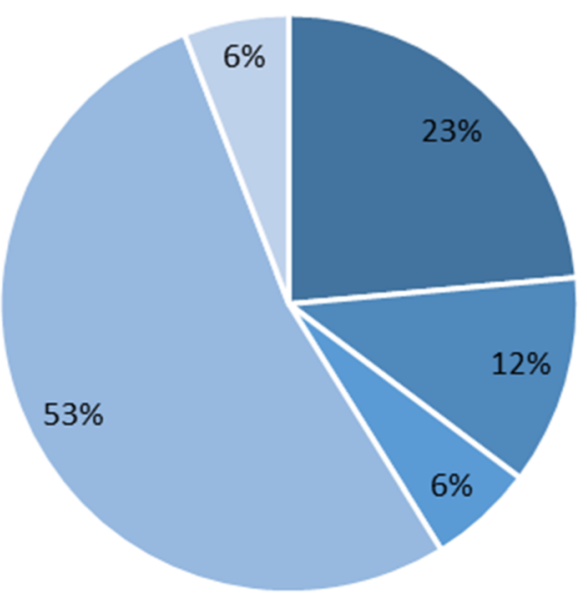

Fig. 4 Planned activities for procurement and logistics for 2012-2016 for districts $\mathbf{a}$ and $\mathbf{b}$

\section{Discussion}

Findings showed that district managers included in the district health annual work plans approximately half of the activities that were identified to bridge gaps for child survival. There was a slight increase in the number of prioritised activities over the 2012/2013 to 2015/2016 period. However, the proportion of activities included in the annual work plans remained practically the same over the 4-year period. Although procurement and logistics-related activities, such as reproducing guidelines, accounted for the most substantial proportion of planned funding in both districts, there was a wide variation in what those activities included. The variation

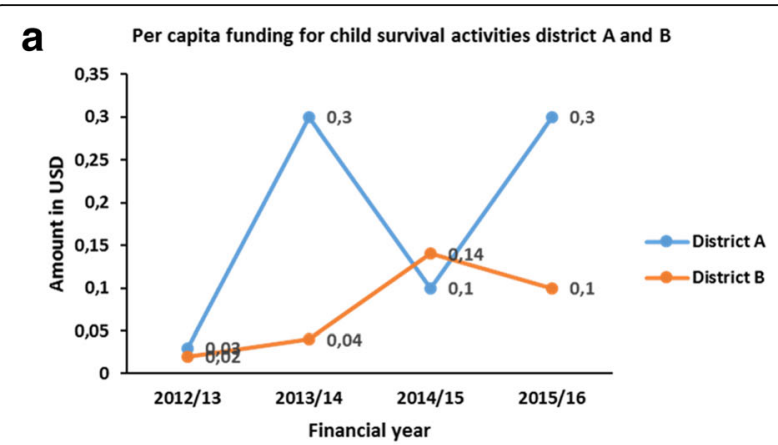

b

Sources of funding as a percentage of the total budget for child survival activities

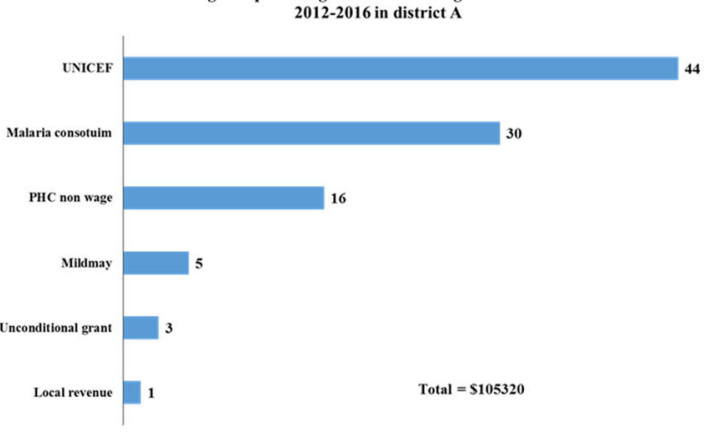

C

C Sources of funding as a percentage of the total budget for child survival activities
2012-2016 in district B

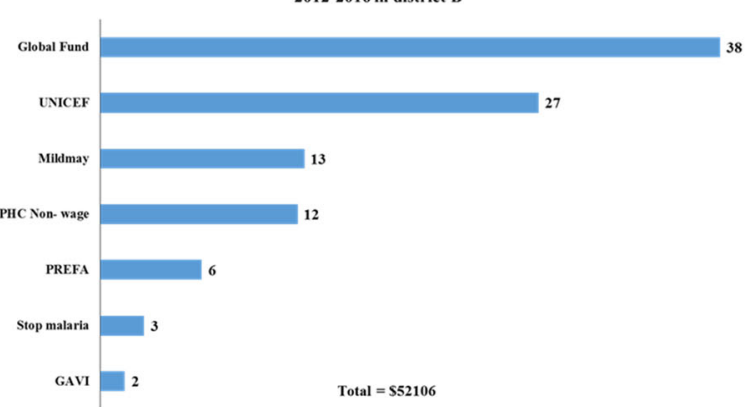

Fig. 5 Planned per capita funding for child survival activities a, and sources of funding (\%) for 2012-2016 b and c

might be an indication that the districts prioritised activities according to their local needs. Child survival activities accounted for between $4 \%$ and $5.5 \%$ of the total planned expenditure on health services, with per capita funding of US\$ 0.3 in one district and US\$ 0.1 in the other. Over the 4 years, donors' contributions accounted for between $47 \%$ and $94 \%$ of the funding for child survival activities.

DHMT members acknowledged that the use of district-specific evidence resulted in practical and robust annual work plans and was beneficial to the district health system. This is similar to findings in a study conducted in India, Nigeria and Ethiopia, where district managers viewed the use of locally generated evidence positively [48]. However, in one of the districts, activities 
that were considered too expensive, and no funds were available, were not prioritised in the work plan. In contrast, in the other district, even those priorities that were unfunded but considered of high priority were included in the work plan and indicated as unfunded. The difference in the action taken showed that the district managers involved in the planning process were not always clear about what should be included in the annual health work plans. Should it be all the activities they consider priorities irrespective of available funding? Or should they prioritise only those activities that can fit within the indicative financing for that financial year? This lack of clarity could be related to the absence of a regional level and the weakened capacity of the $\mathrm{MoH}$ to coordinate, support, monitor and supervise the growing number of districts [5], leading to the deterioration of the planning process. Similar findings were documented by Youngkong et al. [19] in a review study on priority-setting in developing countries. In other studies conducted in sub-Saharan countries by Mutale et al. [49] and Henriksson et al. [4], financial constraints affected decision-making and prioritisation of activities despite the use of district-specific evidence.

The DHMT considered the lack of autonomy or decision space a constraint to the use of district-specific evidence. Similar concerns have been documented in other LIC settings like Ghana, Zambia and the Philippines [50-52]. Although being decentralised, most of the priority-setting is still carried out at the central level with districts following the national guidelines from the $\mathrm{MoH}$ [7]. District managers also reported difficulties in reallocating funds, indicating limited fiscal space. Donors and other partners contributed most of the funding for child survival activities, although, as was demonstrated in another study in Uganda [18], often the donor agencies have their own priorities, which may not always be those of the districts, for example, the geographical area of implementation of programmes may not necessarily be in the areas that have the most need.

Another consideration while using district-specific evidence was the political nature of decision-making and priority-setting. This is not unique to Uganda, Bryant et al. [53] and Goddard et al. [54] also documented politics as a primary consideration in decision-making processes. Another factor that influenced the use of district-specific evidence was influence from multiple funders/stakeholders, as was also reported in a review study on setting priorities for health interventions by Youngkong et al. [19].

\section{Methodological considerations}

The absence of a standard format for the district annual work plan meant that the work plans varied between the districts and even between the different planning cycles.
The variation was not as a result districts identifying context-specific priorities. The difference in formats makes the analysis more difficult to standardise and generalise. As this study was carried out in only two districts that were part of an intervention to improve the use of district-specific evidence in setting priorities in the planning process, results cannot be generalised to all other districts; however, they can be used to inform the planning process in Uganda and countries with similar settings. During the annual health work plan review, analysis of planned activities and not their implementation was done. The analysis also included the proposed expenditure for child survival activities and not the actual spending.

\section{Conclusions}

This study revealed that use of district-specific evidence and a structured process for its utilisation to prioritise activities and make decisions in the planning process at the district level helped systematise an otherwise ad hoc process. By using district-specific evidence, health management teams were able to articulate and advocate for priorities related to child survival. However, the reported limited decision and fiscal space, human resource gaps and inadequate funding did not always allow for the use of district-specific evidence in the planning process. As reflected in the district health annual work plans, districts were heavily dependent on donor funding for child survival activities, which may constrain their ability to use district-specific evidence in the planning process.

The heavy dependence on donor funding raises the question about the usefulness of using district-specific evidence in the reported absence of adequate resources to finance and operationalise the district health annual work plans and the limited decision and fiscal space that the DHMT has to address the gaps identified using the local evidence. Related to this is whether district managers can prioritise activities that reflect the needs of the district as opposed to the interests of the funding partners who provided the bulk of funding for child survival activities.

\section{Abbreviations \\ CODES: Community and District Empowerment for Scale-up project; DHMT: District Health Management Team; DHS: District Health System; LIC: low-income country; MoH: Ministry of Health}

\section{Acknowledgements}

The views expressed are not necessarily those of the Foundation or UNICEF. The authors wish to acknowledge the district health managers for their contribution to the manuscript.

Funding

The Community and District Empowerment for Scale-up (CODES) project was funded by the United States Fund for UNICEF; a grantee of the Bill \& Melinda Gates Foundation (PBA SC/2011/0258). 


\section{Availability of data and materials}

The datasets used and/or analysed during the current study are available from the corresponding author on reasonable request.

\section{Authors' contributions}

DKH was involved in conceptualising study, data collection, analysis, interpretation, writing and finalising of the manuscript. SSP was involved in critical revisions of the manuscript. PW was involved in critical revisions to the manuscript. MF was involved in analysis, interpretation, and critical revisions of the manuscript. All authors read and approved the final manuscript.

\section{Ethics approval and consent to participate}

Ethical clearance for this study was approved by the Uganda National Council of Science and Technology reference number (UNCST-SS 2548). Permission to conduct the study in the district was granted by the district health office. Participation was voluntary, and verbal informed consent was sought for the interview and audio recording before the interview. No payment was given for participating in the interview.

\section{Consent for publication}

No person's data in any form was used.

\section{Competing interests}

The authors declare that they have no competing interests.

\section{Publisher's Note}

Springer Nature remains neutral with regard to jurisdictional claims in published maps and institutional affiliations.

\section{Author details \\ ${ }^{1}$ Karolinska Institutet, Stockholm and Uppsala University, Uppsala, Sweden. ¿United Nations Children's Fund, New York, Karolinska Institutet, Stockholm, Uppsala University, Uppsala, Sweden. ${ }^{3}$ School of Public Health, Kampala and Karolinska Institutet, Makerere University College of Health Sciences, Stockholm, Sweden. ${ }^{4}$ Department of Public Health and Caring Sciences, Uppsala University, Uppsala, Sweden.}

\section{Received: 27 November 2018 Accepted: 30 April 2019}

\section{Published online: 06 June 2019}

\section{References}

1. World Health Organization. Declaration on Strengthening Health Systems Based on Primary Health Care. Harare: WHO; 1987.

2. Government of Uganda. Local Government Act 1997. Kampala: Government of Uganda; 1997.

3. Green E. Decentralization and Development in Contemporary Uganda. Reg Federal Stud. 2015:25(5):491-508.

4. Henriksson DK, Ayebare F, Waiswa P, Peterson SS, Tumushabe EK, Fredriksson M. Enablers and barriers to evidence based planning in the district health system in Uganda; perceptions of district health managers. BMC Health Serv Res. 2017:17:103.

5. Ministry of Health Uganda. Health Sector Strategic \& investment Plan 2010/ 11-2014/15. Kampala: Ministry of Health; 2010

6. Ssengooba F. Uganda's Minimum Health Care Package: Rationing Within the Minimum? Uganda Martyrs University Institutional Repository. 2004. http://ir.umu.ac.ug/xmlui/handle/20.500.12280/1385. Accessed 14 May 2019.

7. Ministry of Health Uganda. Health Sector Development Plan 2015/16-2019/ 20. Kampala: Ministry of Health; 2015.

8. Government of Uganda. Constitution of the Republic of Uganda. Kampala: Government of Uganda; 1995.

9. Dickey C, O'Connell T, Bedford J, Thiede M. Integrating an Approach to Assess UHC Access Barriers into District Health Systems Strengthening in Uganda, Ghana and Rwanda. New York: United Nations Children's Fund; 2014.

10. Campbell OM, Graham WJ. Strategies for reducing maternal mortality: getting on with what works. Lancet. 2006;368(9543):1284-99.

11. Brownson RC, Fielding JE, Maylahn CM. Evidence-based public health: a fundamental concept for public health practice. Annu Rev Public Health. 2009;30:175-201

12. Ham C. Priority setting in health care: learning from international experience. Health Policy. 1997;42(1):49-66.
13. Kapiriri L, Norheim OF, Martin DK. Priority setting at the micro-, meso- and macro-levels in Canada, Norway and Uganda. Health Policy. 2007;82(1):78-94.

14. Curtale F, Musila T, Opigo J, Nantamu D, Ezati IA. District health planning at a time of transition: a critical review and lessons learnt from the implementation of regional planning in Uganda. Int Health. 2016;8(3):162-9.

15. Mitton C, Donaldson C. Health care priority setting: principles, practice and challenges. Cost Eff Resour Alloc. 2004;2(1):3.

16. Odaga J, Henriksson DK, Nkolo C, Tibeihaho H, Musabe R, Katusiime M, et al Empowering districts to target priorities for improving child health service in Uganda using change management and rapid assessment methods. Glob Health Action. 2016;9:30983.

17. Rudan I, Kapiriri L, Tomlinson M, Balliet M, Cohen B, Chopra M. Evidence-based priority setting for health care and research: tools to support policy in maternal, neonatal, and child health in Africa. PLoS Med. 2010;7(7):e1000308.

18. Kapiriri L, Arnesen T, Norheim OF. Is cost-effectiveness analysis preferred to severity of disease as the main guiding principle in priority setting in resource poor settings? The case of Uganda. Cost Effect Resour Alloc. 2004;2(1):1.

19. Youngkong S, Kapiriri L, Baltussen R. Setting priorities for health interventions in developing countries: a review of empirical studies. Tropical Med Int Health. 2009;14(8):930-9.

20. Waiswa P, O'Connell T, Bagenda D, Mullachery P, Mpanga F, Henriksson DK, et al. Community and District Empowerment for Scale-up (CODES): a complex district-level management intervention to improve child survival in Uganda: study protocol for a randomized controlled trial. Trials. 2016;17(1):135.

21. Evidence-Based Medicine Working Group. Evidence-based medicine. A new approach to teaching the practice of medicine. JAMA. 1992;268(17):2420-5.

22. Sackett DL, Rosenberg WM, Gray JA, Haynes RB, Richardson WS. Evidence based medicine: what it is and what it isn't. BMJ. 1996;312(7023):71-2.

23. Klein R. From evidence-based medicine to evidence-based policy? J Health Serv Res Policy. 2000;5(2):65-6.

24. Niessen LW, Grijseels EW, Rutten FF. The evidence-based approach in health policy and health care delivery. Soc Sci Med. 2000;51(6):859-69.

25. Dobrow MJ, Goel V, Upshur RE. Evidence-based health policy: context and utilisation. Soc Sci Med. 2004;58(1):207-17.

26. Rychetnik L, Hawe P, Waters E, Barratt A, Frommer M. A glossary for evidence based public health. J Epidemiol Commun Health. 2004;58(7):538-45.

27. Oxman AD, Lavis JN, Lewin S, Fretheim A. SUPPORT Tools for evidenceinformed health Policymaking (STP) 1: what is evidence-informed policymaking? Health Res Policy Syst. 2009;7(Suppl 1):S1.

28. Walt G, Gilson L. Reforming the health sector in developing countries: the central role of policy analysis. Health Policy Plan. 1994;9(4):353-70.

29. Steen H, Jareg P, Olsen I. Providing a core set of health interventions for the poorTowards Developing a Framework for Reviewing and Planning - A Systemic Approach. Background Document. Oslo: Centre for Health and Social Development; 2001

30. Henriksson KD, Fredriksson M, Waiswa P, Selling K, Swartling Peterson S. Bottleneck analysis at district level to illustrate gaps within the district health system in Uganda. Glob Health Action. 2017:10(1):1327256.

31. O'Connell T, Sharkey A. Reaching Universal Health Coverage Through District Health System Strengthening: Using a Modified Tanahashi Model to Attain Equitable and Effective Coverage. New York: UNICEF; 2013.

32. Tanahashi T. Health service coverage and its evaluation. Bull World Health Organ. 1978;56(2):295-303.

33. Ministry of Health Uganda. Guidelines to the local government planning process Health Sector Supplement. Kampala: Ministry of Health Uganda; 2016.

34. Katahoire AR, Henriksson DK, Ssegujja E, Waiswa P, Ayebare F, Bagenda D, et al. Improving child survival through a district management strengthening and community empowerment intervention: early implementation experiences from Uganda. BMC Public Health. 2015;15(1):797.

35. Kapiriri L, Norheim OF, Heggenhougen K. Public participation in health planning and priority setting at the district level in Uganda. Health Policy Plan. 2003;18(2):205-13.

36. Polit DF, Beck CT. Nursing Research: Generating and Assessing Evidence for Nursing Practice. Philadelphia: Lippincott Williams \& Wilkins; 2008.

37. Creswell JW. Mixed-method research: Introduction and application. In: Cizek GJ, editor. Handbook of Educational Policy. San Diego: Academic Press; 1999. p. $455-72$

38. Creswell JW. Research Design: Qualitative, Quantitative, and Mixed Methods Approaches. 2nd ed. Thousand Oaks: Sage; 2003. 
39. Curry LA, Krumholz HM, O'Cathain A, Plano Clark VL, Cherlin E, Bradley EH. Mixed methods in biomedical and health services research. Circ Cardiovasc Qual Outcomes. 2013;6(1):119-23.

40. Creswell JW, Plano Clark VL. Designing and Conducting Mixed Methods Research. Thousand Oaks: Sage; 2007.

41. Jones R. Why do qualitative research? BMJ. 1995;311(6996):2.

42. Patton MQ. Qualitative interviewing. Qual Res Eval Methods. 2002;3:344-7.

43. World Health Organization. Decentralization and Health Systems Change: A Framework for Analysis, Revised Working Document. Geneva: WHO; 1995.

44. Daniel WW, Cross CL. Biostatistics: A Foundation for Analysis in the Health Sciences. Massachusetts: Wiley; 1995.

45. Joffe H. Thematic analysis. In: Qualitative Research Methods in Mental Health and Psychotherapy: A Guide for Students and Practitioners. New Jersey: Wiley; 2012. p. 210-23.

46. Boyatzis RE. Thematic Analysis and Code Development: Transforming Qualitative Information. London and New Delhi: Sage Publications; 1998.

47. Braun V, Clarke V. Using thematic analysis in psychology. Qual Res Psychol. 2006;3(2):77-101.

48. Avan BI, Berhanu D, Umar N, Wickremasinghe D, Schellenberg J. District decision-making for health in low-income settings: a feasibility study of a data-informed platform for health in India, Nigeria and Ethiopia. Health Policy Plan. 2016;31(Suppl_2):ii3-ii11.

49. Mutale W, Chintu N, Amoroso C, Awoonor-Williams K, Phillips J, Baynes C, et al. Improving health information systems for decision making across five sub-Saharan African countries: Implementation strategies from the African Health Initiative. BMC Health Serv Res. 2013;13((Suppl 2)):S9.

50. Bossert TJ, Beauvais JC. Decentralization of health systems in Ghana, Zambia, Uganda and the Philippines: a comparative analysis of decision space. Health Policy Plan. 2002;17(1):14-31.

51. Somanje H, Barry SP, Dramé B, Mwikisa-Ngenda C. Health systems strengthening: improving district health service delivery and community ownership and participation. Afr Health Monitor. 2012;15:48-54.

52. Wickremasinghe D, Hashmi IE, Schellenberg J, Avan Bl. District decisionmaking for health in low-income settings: a systematic literature review. Health Policy Plan. 2016;31(Suppl 2)):ii12-24.

53. Bryant JH, Coulter A, Ham C. Health priority dilemmas in developing countries. In: Coulter A, Ham C (eds.). The Global Challenge of Health Care Rationing. Buckingham: Open University Press; 2000. p. 63-74.

54. Goddard M, Hauck K, Preker A, Smith PC. Priority setting in health - a political economy perspective. Health Econ Policy Law. 2006; (1):79-90.

Ready to submit your research? Choose BMC and benefit from:

- fast, convenient online submission

- thorough peer review by experienced researchers in your field

- rapid publication on acceptance

- support for research data, including large and complex data types

- gold Open Access which fosters wider collaboration and increased citations

- maximum visibility for your research: over $100 \mathrm{M}$ website views per year

At BMC, research is always in progress.

Learn more biomedcentral.com/submissions 